\title{
Castelculier - Lamarque
}

\section{Claude Gras}

\section{OpenEdition \\ Journals}

Édition électronique

URL : http://journals.openedition.org/adlfi/2806

ISSN : 2114-0502

Éditeur

Ministère de la culture

Référence électronique

Claude Gras, "Castelculier - Lamarque », ADLFI. Archéologie de la France - Informations [En ligne], Aquitaine, mis en ligne le 01 mars 2008, consulté le 20 avril 2019. URL : http://

journals.openedition.org/adlfi/2806

Ce document a été généré automatiquement le 20 avril 2019

(c) Ministère de la Culture et de la Communication, CNRS 


\title{
Castelculier - Lamarque
}

\author{
Claude Gras
}

Identifiant de l'opération archéologique : 025436

Date de l'opération : 2008 (EX)

1 C'est à la suite d'un projet de creusement d'une piscine dans l'emprise de la pars urbanade la villade Lamarque à Castelculier que nous sommes intervenus.

2 Cette zone est aujourd'hui occupée par un lotissement qui jouxte le jardin archéologique. La parcelle concernée se situe dans le prolongement nord de la galerie ouest du péristyle de la cour de la villamis au jour lors des campagnes de fouilles précédentes. Cette villa aristocratique, dont la construction et les différents états s'étant de la fin du I ${ }^{\mathrm{er}} \mathrm{s}$. au V s. apr. J.-C., a fait l'objet de six campagnes de fouilles : de 1986 à 2000.

3 Seule une partie de l'aille sud-ouest de la pars urbana,soit $3500 \mathrm{~m}^{2}$ environ, a fait l'objet d'une fouille intégrale qui a mis au jour l'angle sud-ouest du péristyle et de la cour ainsi que certaines pièces d'habitation et l'ensemble quasi complet de la zone thermale, dont l'ensemble a été mis en valeur en 1998 sous la forme d'un jardin archéologique. L'emprise de la piscine est d'environ $35 \mathrm{~m}^{2}$.

4 Trois murs ont été mis au jour. L'un, dégagé sur $8,75 \mathrm{~m}$, d'orientation sud-nord, est le prolongement immédiat du mur extérieur (ouest) du péristyle visible dans le jardin archéologique. Les deux autres d'orientation est-ouest sont perpendiculaires à ce dernier. Le plus au sud a été dégagé sur une longueur de $1 \mathrm{~m}$ et le second au nord du précédent, sur 1,25 $\mathrm{m}$. L'assise supérieure subsistante du mur sud-nord du péristyle est apparue à partir d'une profondeur de $1,40 \mathrm{~m}$, sa hauteur moyenne conservée n'excède pas $0,35 \mathrm{~m}$. Son orientation correspond très exactement à celle établie par Philippe Jacques. Les deux murs d'orientation ouest-est qui s'y raccordent font sensiblement la même hauteur.

5 Pour ce qui est des nouvelles structures mises au jour, un niveau régulier d'épandage de matériaux apparait sur toute la surface de la fosse à 1,40 m environ de profondeur : ce niveau semble correspondre à des structures antérieures à l'implantation de la galerie. 
6 Enfin, nous avons mis au jour les vestiges de la continuité du mur ouest de la galerie du péristyle visible dans le jardin archéologique ainsi que l'amorce de deux murs qui lui sont perpendiculaires. D'après la céramique, ils sont datables du $\mathrm{III}^{\mathrm{e}} \mathrm{s}$. et peuvent compléter les structures du balnéaire dont seul le frigidariumest visible dans le jardin archéologique et dont la datation se situe entre le $\mathrm{III}^{\mathrm{e}} \mathrm{s}$. et le $\mathrm{V}^{\mathrm{e}} \mathrm{s}$..

7 Gras Claude

INDEX

Index chronologique : Antiquité romaine, Empire romain

Index géographique : Aquitaine, Lot-et-Garonne (47), Castelculier

operation Expertise (EX)

Thèmes : céramique gallo-romaine, cour, galerie, mur, péristyle, thermes privés, villa

\section{AUTEURS}

CLAUDE GRAS

BEN 